\title{
CMAJ at 100: our voice, our future
}

\author{
Paul C. Hébert MD MHSc, Ken Flegel MDCM MSc, Matthew B. Stanbrook MD PhD, \\ Noni MacDonald MD MSc, Kim Barnhardt
}

$\mathrm{A}$ s society and health care have evolved, so too has CMAJ. Indeed, the journal is a reflection of the society in which it is firmly rooted. With its 100 -year history and the many successes highlighted by CMA President Dr. Jeffrey Turnbull, ${ }^{1}$ CMAJ is ready to move into its second century.

$C M A J$ has sought to disseminate original research, provide up-to-date advice on clinical issues and present a diversity of views on public policy issues. We encourage open debate and dialogue and advocate for change. However, we have had to learn the value of editorial independence and how best to protect it.

Over the years, the journal has published leading-edge knowledge for doctors, from the discovery of insulin to the beginnings of evidencebased medicine to the unlocked potential of population health services research. Medical research in $C M A J$ has covered the scientific spectrum, from timeless descriptions of laboratory methods still used half a century later to adverse events and interactions of the newest drugs. CMAJ has been providing information about public health threats from bulletins in the early 20th century to timely electronic publications on the new aggressive strains of Clostridium difficile and the 21st century pandemics of SARS and H1N1 influenza.

The journal has also played a lead role in health care debates of the day and continues to do so. Topics have included the link between sun exposure and skin cancer (1938), the dangers of smoking (1960), contraception, abortion and AIDS (1983), food security (2009) and euthanasia (2010). We have taken a strong stance in support of the Canada Health Act and our publicly funded health systems. In 2005, after CMAJ published a news article on problems of access to Plan B, the morning-after contraceptive pill, Ontario pharmacists dropped the screening form over which there were privacy concerns. And just last fall, the journal sounded the alarm over Health Canada's decision to cancel plans to update tobacco warning labels.

Canada's social fabric is now far more ethnically diverse, older and urban than it was a century ago. One hundred years ago, in the preantibiotic era, infectious diseases such as typhoid, tuberculosis and syphilis were substantial public health challenges. ${ }^{2}$ Shockingly, Canada's infant mortality rate was in the triple digits. CMAJ's content reflected this.

We have since been moving from our rural roots to large health care networks and urban practices with complex health needs and therapeutic options. In spite of these many changes, we continue to be a credible and informed voice for our readers - the core of our mission.

The information age has created a deluge of medical information - some of it suspect, some of it downright wrong - CMAJ's peer review processes and clear rules guiding competing interests have combined to make the journal a credible source of information.

What does the future hold for CMAJ? To meet the needs of our global readers, we plan to tailor content. As a first step, we will focus our print journal to a Canadian readership. We will include more practice-related articles such as reviews, guidelines, short clinical articles and images. With our electronic journal, we plan to build community by encouraging a lively exchange of ideas and increase interaction with, and among, readers and authors. We will expand the content selection and deliver it the way our readers want it, whether online, on smartphones or by old-fashioned snail mail, ultimately to improve health decisions in clinical care.

Just as health was a major concern in 1911, health care and its myriad issues will feature prominently in public discourse in the foreseeable future. With the forthcoming health accord negotiations, serious systemic problems such as shortages of long-term care facilities, the lack of a national pharmacare strategy and medicare costs that continue to consume a greater proportion of governments' budgets, there will be no dearth of issues to fill our pages.

CMAJ's independent voice and 100-year reputation will ensure that the journal remains a leading forum in which to read about the science and public policy issues of the day.

\section{References}

1. Turnbull J. 100 years and counting. CMAJ 2011;183:16.

2. Scarlett EP. Fifty years of medicine: 1911-1961. CMAJ 1961; 84:6-10.
Editor-in-Chief (Hébert) Senior Associate Editor (Flegel), Deputy Editor, Scientific (Stanbrook),

Section Editor, Public Health (MacDonald),

Senior Strategist,

Communications and

Partnerships (Barnhardt), CMAJ

Competing interests: See www.cmaj.ca/misc /cmaj_staff.dtl

CMAJ 2011. DOI:10.1503 /cmaj.101832 